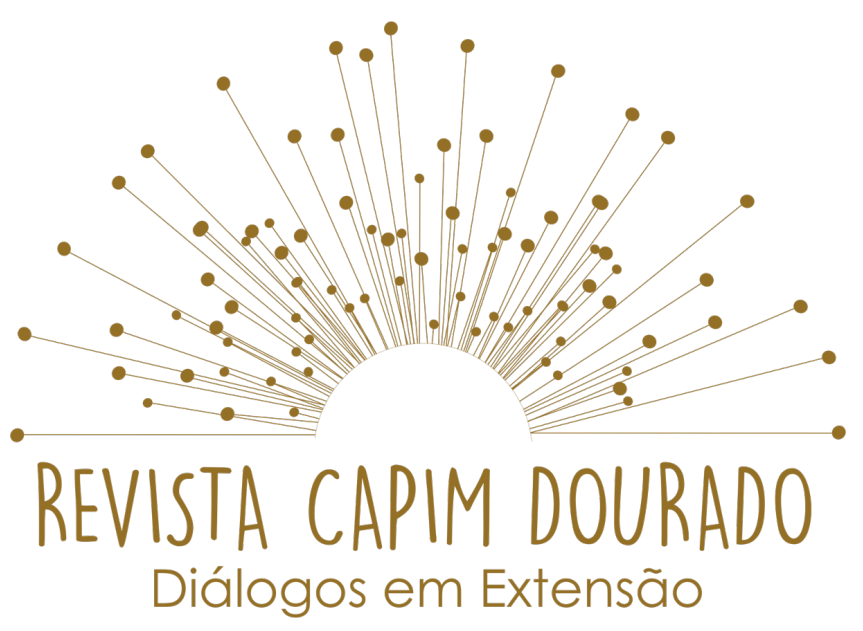

ISSN n² 2595-7341

Vol. 3, n. 1, Janeiro-Abril, 2020

DOI: http://dx.doi.org/10.20873/uft.2595-7341.2020v3n1p197

\title{
USO DE PROJETOS INTEGRADORES COMO INSTRUMENTO DE FOMENTO À INOVAÇÃO E INTEGRAÇÃO ENTRE EMPRESAS E ESTUDANTES: Caso CETEC Palmas
}

USE OF INTEGRATING PROJECTS AS AN INSTRUMENT TO PROMOTE INNOVATION AND INTEGRATION BETWEEN COMPANIES AND STUDENTS: Case of CETEC Palmas

USO DE PROYECTOS INTEGRANTES COMO INSTRUMENTO PARA PROMOVER LA INNOVACIÓN E INTEGRACIÓN ENTRE EMPRESAS Y ESTUDIANTES: Caso CETEC Palmas

\author{
Wellington Rocha Santos ${ }^{1}$ \\ Aron Rodrigo Batista ${ }^{2}$ \\ Francisco Gilson Rebouças Porto Junior ${ }^{3}$
}

\section{RESUMO}

Este trabalho apresenta a experiência obtida com o uso de Projetos Integradores nos cursos da Habilitação Técnica e da Aprendizagem Industrial do Centro de Educação e Tecnologia de Palmas. O uso da integração entre teoria e prática implica em garantir a complementaridade que se estabelece entre essas duas dimensões, possibilitando ao aluno aplicar os fundamentos e capacidades em

\footnotetext{
${ }^{1}$ Mestrando no Mestrado Profissional em Propriedade Intelectual e Transferência de Tecnologia para Inovação; Possui Pós-Graduação em Gestão Estratégica da Inovação e PCT pela UFT Palmas; Pós-Graduação em Inovação em Mídias Interativas pela UFG Goiânia; Pós-Graduação em Educação Profissional e Tecnológica pelo CETIQT Rio de Janeiro; Graduado em Sistemas de Informação pelo Centro Universitário Luterano de Palmas. É instrutor Nível III - Tecnologia da Informação - SENAI CETEC PALMAS - Departamento Regional de Tocantins. E-mail: wel.rocha.santos@gmail.com.

${ }^{2}$ Mestre em Comunicação e Sociedade pelo PPGCOM-UFT. E-mail: aron@mail.uft.br.

3 Jornalista. Doutor em Comunicação e Culturas Contemporâneas (UFBA). Professor do OPAJE/PPGCOM/PROFNIT. E-mail: gilsonportouft@gmail.com.
} 


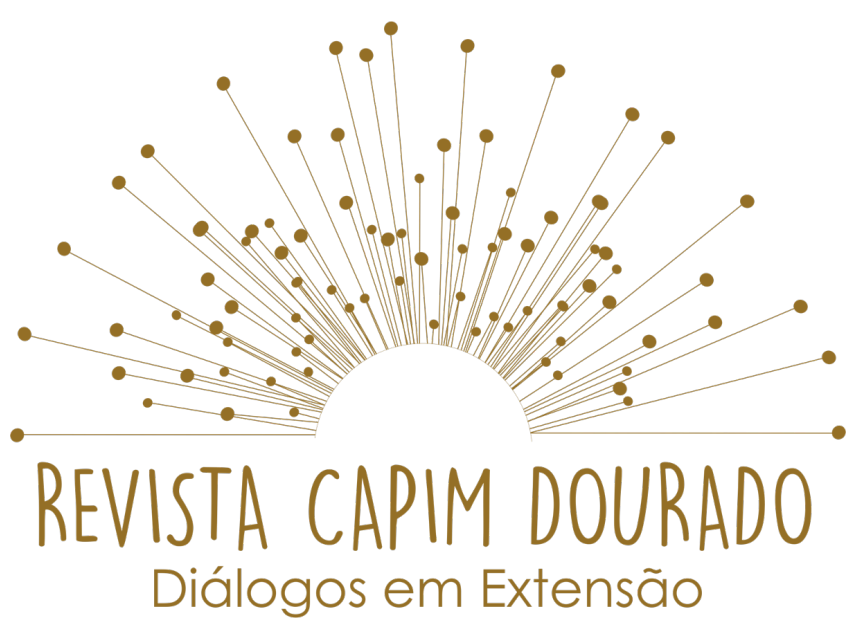

ISSN n² 2595-7341

Vol. 3, n. 1, Janeiro-Abril, 2020

DOI: http://dx.doi.org/10.20873/uft.2595-7341.2020v3n1p197

sua prática profissional diária. A integração entre teoria e prática habilita os estudantes a avaliar e explicitar caminhos e alternativas na resolução de problemas, além de possibilitar a transferência das aprendizagens no enfrentamento de situações inusitadas e mais complexas. Sendo assim, os projetos integradores levam os estudantes à geração de novas ideias, que podem se traduzir em produtos (bens ou serviços) com valor agregado. A interação entre estudantes e empresas mobiliza a criatividade, estimulando o livre pensar, o interesse pelo novo, a imaginação e o pensamento prospectivo com o objetivo de lançar o olhar para a inovação. Ao incentivar o pensamento criativo, o uso de projetos em empresas reais oportuniza aprendizagens que vão além da mera reprodução da realidade, propiciando a descoberta de novas perspectivas e de soluções ainda não pensadas.

PALAVRAS-CHAVES: Integração; Inovação; Educação; Empresas.

\section{ABSTRACT}

This work presents the experience obtained with the use of Integrative Projects in the Technical Qualification and Industrial Learning courses of the Center of Education and Technology of Palmas. The use of the integration between theory and practice implies ensuring the complementarity that is established between these two dimensions, enabling the student to apply the fundamentals and abilities in their daily professional practice. The integration between theory and practice enables students to evaluate and explain ways and alternatives in solving problems, as well as making it possible to transfer learning in the face of unusual and complex situations. Thus, integrating projects lead students to generate new ideas, which can translate into value-added products (goods or services). The interaction between students and companies mobilizes creativity, stimulating free thinking, interest in the new, imagination and prospective thinking with the aim of casting the eye for innovation. By encouraging creative thinking, the use of projects in real companies allows learning that goes beyond the mere reproduction of reality, propitiating the discovery of new perspectives and solutions not yet thought out

KEYWORDS: Integration; Innovation; Education; Companies. 


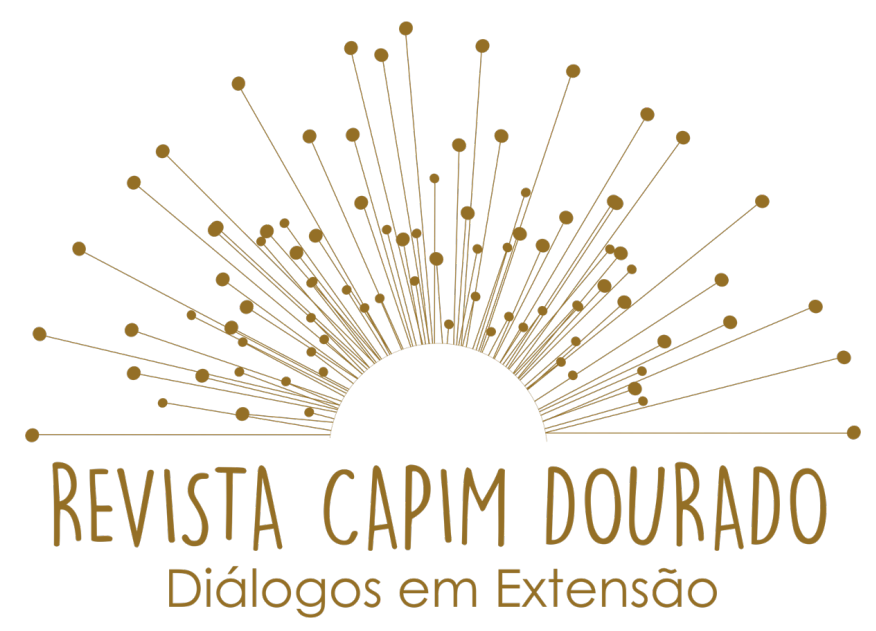

ISSN n² 2595-7341

Vol. 3, n. 1, Janeiro-Abril, 2020

DOI: http://dx.doi.org/10.20873/uft.2595-7341.2020v3n1p197

\section{RESUMEN}

Este trabajo presenta la experiencia obtenida con el uso de Proyectos Integradores en los cursos de Calificación Técnica y Aprendizaje Industrial del Centro de Educación y Tecnología de Palmas. El uso de la integración entre la teoría y la práctica implica garantizar la complementariedad que se establece entre estas dos dimensiones, lo que permite al estudiante aplicar los fundamentos y habilidades en su práctica profesional diaria. La integración entre teoría y práctica permite a los estudiantes evaluar y explicar caminos y alternativas en la resolución de problemas, además de permitir la transferencia del aprendizaje para hacer frente a situaciones inusuales y más complejas. Así, los proyectos integradores llevan a los estudiantes a generar nuevas ideas, que pueden traducirse en productos (bienes o servicios) con valor agregado. La interacción entre estudiantes y empresas moviliza la creatividad, estimula el pensamiento libre, el interés por lo nuevo, la imaginación y el pensamiento prospectivo con el objetivo de mirar hacia la innovación. Al fomentar el pensamiento creativo, el uso de proyectos en empresas reales brinda oportunidades de aprendizaje que van más allá de la mera reproducción de la realidad, permitiendo el descubrimiento de nuevas perspectivas y soluciones que aún no se han pensado.

PALABRAS CLAVE: Integración; Innovación; Educación; Empresas.

Recebido em: 01.10.2019. Aceito em: 09.10.2019. Publicado em: 01.01.2020. 


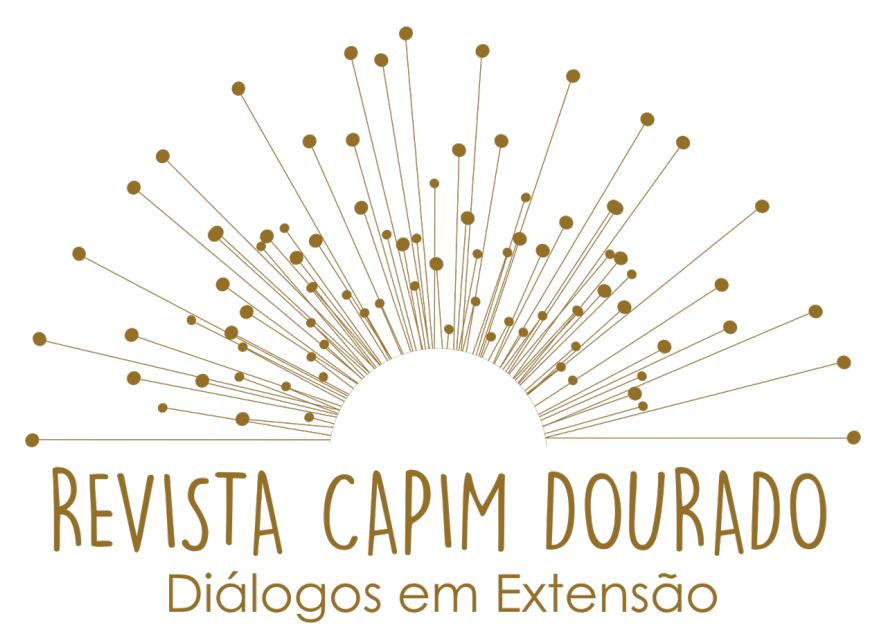

ISSN n² 2595-7341

Vol. 3, n. 1, Janeiro-Abril, 2020

DOI: http://dx.doi.org/10.20873/uft.2595-7341.2020v3n1p197

\section{INTRODUÇÃO}

A inovação é a grande abordagem desta época, empresas, universidades, organizações e instituições públicas e privadas buscam constantemente a inclusão deste tema em seu ecossistema organizacional. O desafio é alinhar as rotinas e processos aos instrumentos e dinâmicas que podem fomentar a inovação.

No mundo empresarial atual, a inovação, como disciplina, não alcançou o estágio de desenvolvimento capaz de satisfazer a necessidade premente de inovar. Constatamos que, em diversas empresas nas quais a inovação é levada em consideração, a necessidade supera a capacidade. Uma estatística é reveladora: embora $96 \%$ dos executivos considerem a criatividade essencial para suas empresas, surpreendentemente, apenas 23\% deles tiveram êxito em torná-la parte integrante da empresa. (KOTLER E BES, 2011. p. 15).

Neste contexto surge a oportunidade de realizar a integração entre as empresas que prezam pela inovação e as instituições educacionais que buscam em seus processos desenvolver o ensino através de pesquisas e aplicações inovadoras para a sociedade. De acordo com o Manual de Oslo (OCDE, 2005, p. 11) "a geração, a exploração e a difusão do conhecimento são fundamentais para o crescimento econômico, o desenvolvimento e o bem-estar das nações. Assim, é fundamental dispor de melhores medidas de inovação". E essas medidas podem ser implementadas em diversos setores da sociedade, cada qual com seu nível de profundidade e abrangência.

O conhecimento e a tecnologia tornaram-se cada vez mais complexos, aumentando a importância das interações entre empresas e outras organizações como uma forma de adquirir 


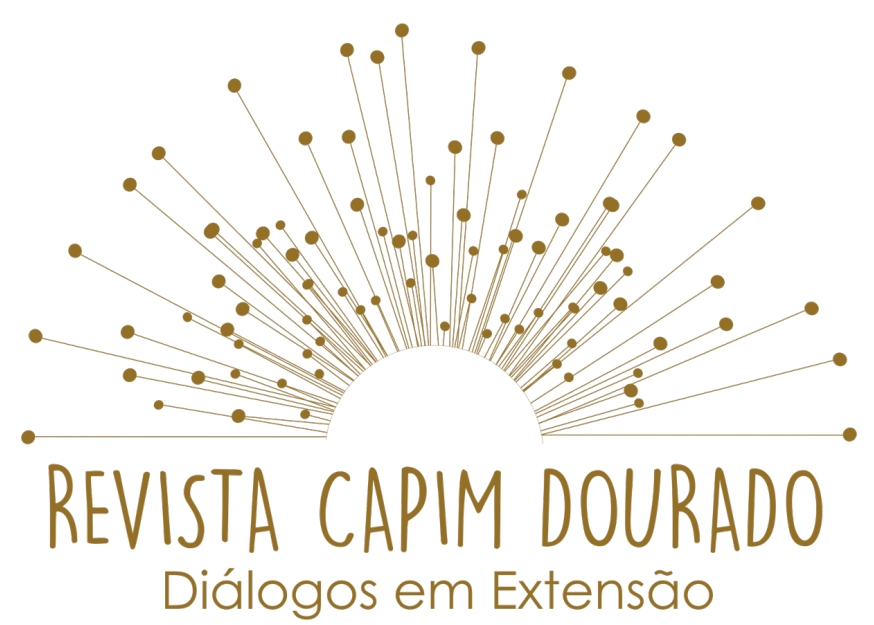

ISSN n² 2595-7341

Vol. 3, n. 1, Janeiro-Abril, 2020

DOI: http://dx.doi.org/10.20873/uft.2595-7341.2020v3n1p197

conhecimento especializado. Um desenvolvimento econômico paralelo é o crescimento da inovação em serviços nas economias avançadas. (OCDE, 2005, p. 35).

O método utilizado neste trabalho é uma pesquisa quanti-qualitativa que busca analisar o ecossistema criado para realização da integração entre empresas e o centro educacional, desvendar o processo e os instrumentos utilizados para implementação dos projetos e o papel desempenhado pelas empresas e pelos estudantes. A conceituação dos temas inovação e projetos integradores será feita por meio de pesquisa bibliográfica.

\section{Resultados e Discussões}

O CETEC é uma instituição de ensino profissionalizante e promotora de tecnologia e inovação para a indústria do estado do Tocantins pertencente ao SENAI/TO, integrante do Sistema Indústria ao lado da CNI, do SESI e do IEL possuindo como propósito "formar profissionais e prover soluções tecnológicas para tornar a indústria competitiva e inovadora" (SENAI/TO, 2017, online).

Segundo MEGHNAGI (1999, p. 55), a produção flexível varia no tempo e no espaço e a competência profissional demandada não pode mais ser explicada a partir de uma simples série de atuações constantes. Ela se caracteriza, sobretudo, pela variedade teoricamente ilimitada de questões e de imprevistos a serem enfrentados, adequando e reelaborando o saber adquirido. Esta variedade, neste sentido flexível, passou a exigir um conjunto complexo de conhecimentos e habilidades, muito além do tradicional repertório descritivo das qualificações. 


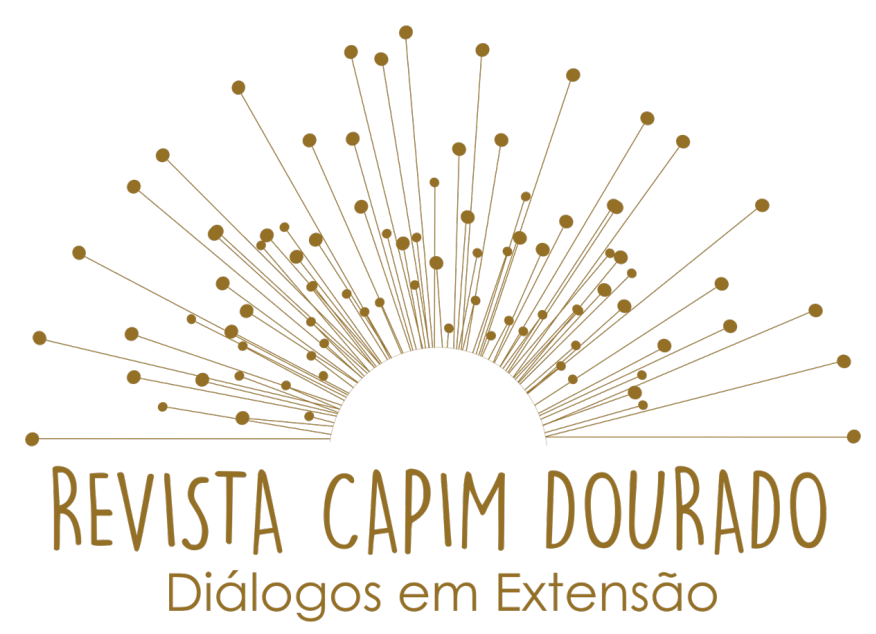

ISSN n² 2595-7341

Vol. 3, n. 1, Janeiro-Abril, 2020

DOI: http://dx.doi.org/10.20873/uft.2595-7341.2020v3n1p197

As atuais demandas da 'Sociedade do Conhecimento' levam a uma crise das próprias carreiras profissionais, pela exigência de novas habilidades e competências, sem desconsiderar a competência técnica: trabalho em equipe, adaptação a situações novas, aplicação de conhecimento e aprendizagens, atualização contínua pela pesquisa, abertura à crítica, busca de soluções criativas, inovadoras, fluência em vários idiomas, domínio do computador e de processos de informática, gestão de equipe, diálogo entre pares. (MASETTO, 2004, p. 199).

Nestas reflexões supracitadas podemos realizar uma análise crítica das reais competências que os estudantes atuais estão desenvolvendo e da importância de determinados saberes para a execução prática e técnica na indústria.

O Desafio Senai de Projetos Integradores (DSPI) é uma iniciativa do Departamento Nacional do Senai que tem por objetivo fomentar o uso de Metodologia Senai de Educação Profissional (MSPE) e o empreendedorismo como processo de inovação pela educação. (GP INOVAÇÃO, 2017, online).

Inicialmente uma das preocupações na implantação do DSPI foi caracterizar o conceito de inovação para os estudantes e para as empresas. Neste contexto buscou-se a compreensão do Manual de OSLO para trabalhar com a inovação de baixa e média tecnologia.

A inovação nas indústrias de baixa e média tecnologia (BMTs) recebem frequentemente menos atenção do que a inovação em indústrias de alta tecnologia. Entretanto, a inovação em BMTs pode ter um impacto substancial no crescimento econômico, devido ao peso desses setores na economia. BMTs são geralmente caracterizadas pela inovação incremental [...]. Dessa forma, as atividades de inovação são geralmente centradas na eficiência da produção, na diferenciação de produto e no marketing. Exemplos proeminentes são o uso de TIC e de 


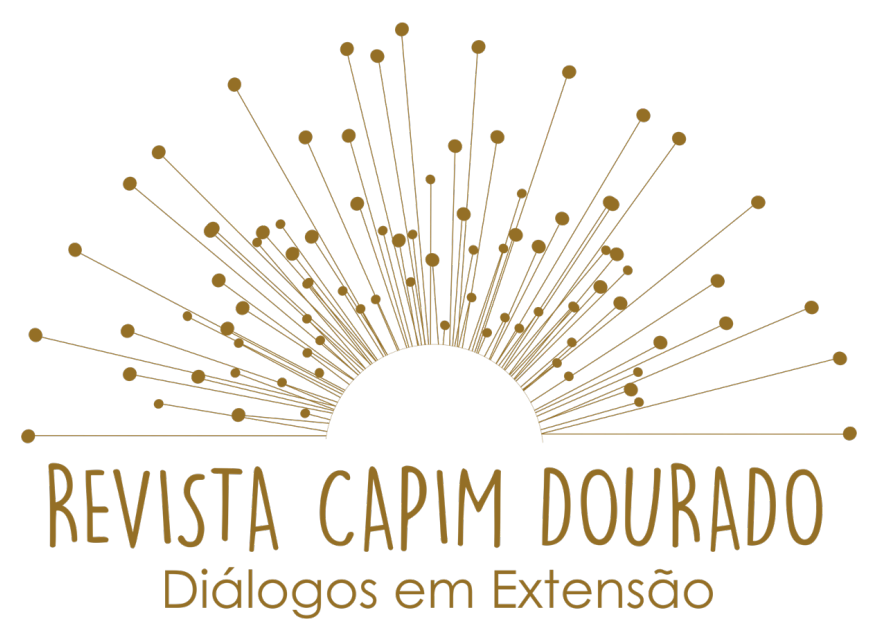

ISSN n² 2595-7341

Vol. 3, n. 1, Janeiro-Abril, 2020

DOI: http://dx.doi.org/10.20873/uft.2595-7341.2020v3n1p197

biotecnologia (por exemplo, no processamento de alimentos) no desenvolvimento de novos produtos e processos de produção. (OCDE, 2005, p. 47).

Além disso, buscou-se também a compreensão da inovação em pequenas e médias empresas, tendo em vista que a indústria no estado do Tocantins ainda se mostra incipiente, sendo a maior demanda por melhoria advinda deste segmento empresarial.

As pequenas e médias empresas (PMEs) possuem necessidades mais especializadas em suas atividades. Isso aumenta a importância de uma interação eficiente com outras empresas e com instituições públicas de pesquisa para $P \& D$, troca de conhecimentos e, potencialmente, para comercialização e atividades de marketing [...]. As pesquisas podem fornecer mais dados sobre o grau em que as restrições financeiras afetam a capacidade de inovar das PMEs. (OCDE, 2005, p. 47-48).

Após as conceituações definiu-se o fluxo de execução do DSPI. Todo o processo foi executado através da Plataforma de Gestão de Projetos e Inovação do SENAI ${ }^{4}$.

\footnotetext{
${ }^{4}$ www.plataforma.gpinovacao.senai.br - necessário realizar cadastro para acesso / cadastro gratuito.
} 


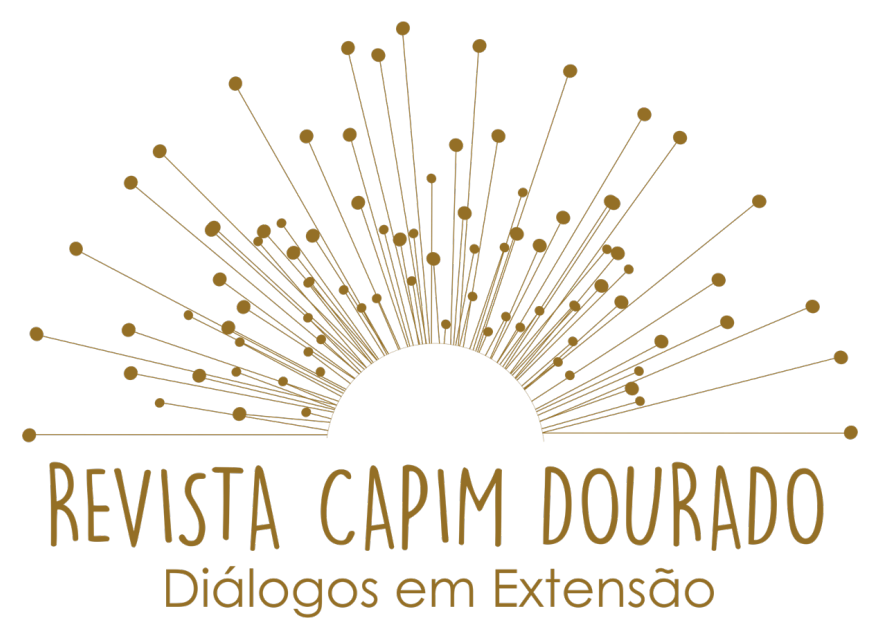

ISSN n² 2595-7341

Vol. 3, n. 1, Janeiro-Abril, 2020

DOI: http://dx.doi.org/10.20873/uft.2595-7341.2020v3n1p197

Figura 1 - Fluxo do Processo DSPI 2017

A primeira etapa do fluxo foi o Cadastro de Demandas onde representantes de empresas, coordenadores e docentes realizaram o cadastro de demandas para serem solucionadas pelos estudantes. No estado do Tocantins foram cadastradas 10 demandas de 7 diferentes empresas/institutos, entre elas: Primia Arquitetura Ltda - Me; Telemont Engenharia De Telecomunicações S/A; Instituto De Natureza Do Tocantins - Naturatins; Tonolucro Franchising Ltda; Fundação Fé E Alegria Do Brasil; Artemsite Tecnologia Em Internet Ltda Me; Vli Valor Logístico Integrado. As empresas que foram convidadas a participar acessaram a plataforma GP de Inovação e realizam o cadastro de problemas específicos que precisavam de algum tipo de solução inovadora. Buscou-se esclarecer que o objetivo do DSPI é pedagógico e faz parte de um projeto educacional que visa o desenvolvimento de capacidades como, criatividade e visão inovadora e sistêmica nos estudantes. 


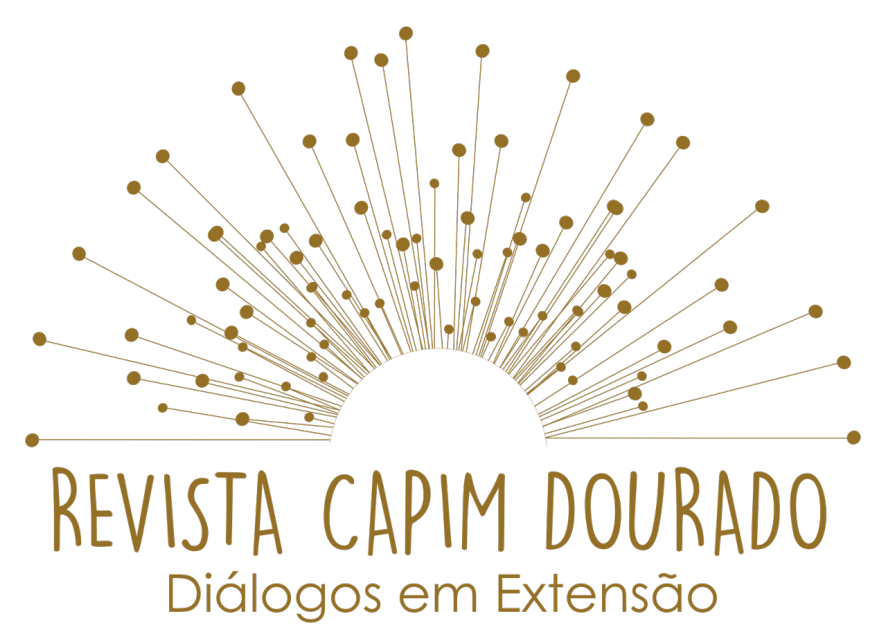

ISSN n² 2595-7341

Vol. 3, n. 1, Janeiro-Abril, 2020

DOI: http://dx.doi.org/10.20873/uft.2595-7341.2020v3n1p197

Após o processo de levantamento das demandas, foi realizada a etapa de definição das equipes participantes. Durante o período, a comissão interna do DSPI no Estado do Tocantins incentivou os alunos dos Curso Técnicos e da Aprendizagem Industrial a participarem do desafio e submeterem ideias às demandas cadastradas. Ao todo foram cadastradas 24 equipes com soluções do Tocantins para demandas de diversos lugares do Brasil. Todas as soluções cadastradas pelo Estado do Tocantins estão disponíveis na Plataforma GP de Inovação ${ }^{5}$.

As equipes juntamente com seus orientadores realizaram 0 desenvolvimento dos projetos com os seguintes instrumentos: Projeto, Canvas, Pitch e Protótipo. Todos os vídeos dos projetos do estado do Tocantins estão disponíveis para acesso público no Canal do Youtube do CETEC Palmas ${ }^{6}$.

Foi realizada, após a participação no processo, uma pesquisa com os estudantes, pela coordenação dos Projetos integradores/CETEC- Palmas, sobre a eficácia da utilização de Projetos Integradores no processo de ensino: $62,7 \%$ dos entrevistados afirmaram ter aprendido mais desenvolvendo projetos integradores do que nas aulas tradicionais; $21,1 \%$ consideram os dois métodos eficientes; $16,2 \%$ afirmaram aprender mais com aulas tradicionais.

\footnotetext{
${ }^{5}$ Lista de Demandas Cadastradas por empresas do Tocantins na Plataforma GP de Inovação do SENAI:

http://plataforma.gpinovacao.senai.br/plataforma/ideia?nome $=$ \&estado $=27 \&$ desafio $=34 \&$ depa rtamento $=28 \&$ demanda $=$ \&buscar $=$ Pesquisar.

${ }^{6}$ Canal com vídeos (Pitchs) dos Projetos Integradores do Estado do Tocantins: $<$ https://www.youtube.com/watch?v=9gNQrshV4kg\&list=PLfcEv15hYG9rPP47zWlbnubLK48kHv $2 \mathrm{Zr}>$
} 


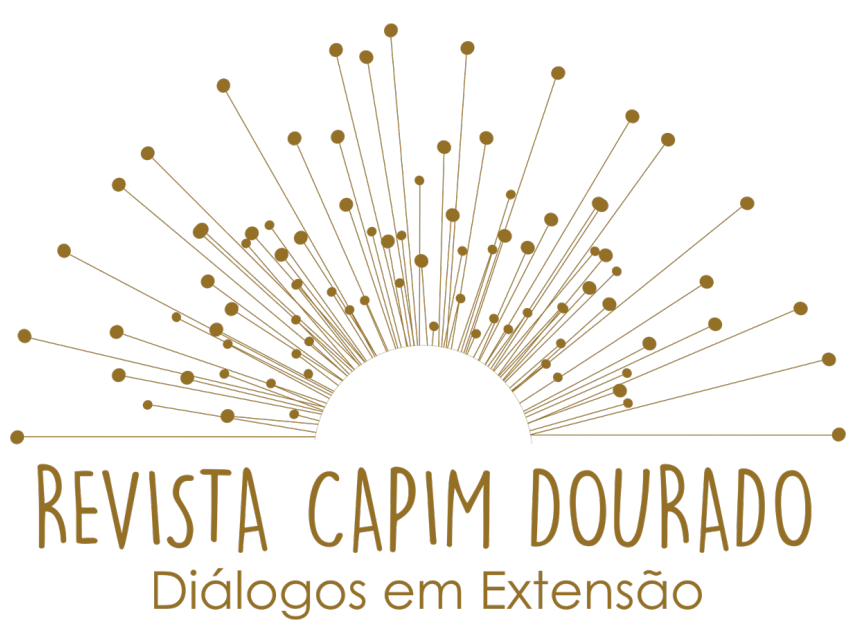

ISSN n² 2595-7341

Vol. 3, n. 1, Janeiro-Abril, 2020

DOI: http://dx.doi.org/10.20873/uft.2595-7341.2020v3n1p197

Ainda questionados se participariam novamente do DSPI: $64,9 \%$ dos estudantes afirmaram que certamente voltariam a participar; 16,9\% informaram participar se as demandas fossem melhor esclarecidas; $12,3 \%$ afirmaram que voltariam se o processo fosse mais rápido e prático; 5,9\% afirmaram que não tinham interesse em participar novamente.

Da etapa regional realizada no Tocantins foram selecionados 6 projetos (3 - habilitação técnica / 3 - aprendizagem industrial) para representarem o estado na etapa nacional. A escolha dos projetos foi feita por banca avaliadora composta por representantes da indústria, SEBRAE, Governo do Estado do Tocantins e Agência de Fomento à Inovação. A lista com os finalistas de cada estado pode ser encontrada na plataforma GP de Inovação do SENAI'.

\section{Conclusões}

Assim sendo, a experiência do DSPI, relatada aqui, ilustra a amplitude das vivências com situações-problemas organizadas no formato de projetos com características inovadoras. Acreditamos que são vivências como essas, que oferecem a dimensão dos rumos da Educação Profissional. Nesse sentido, docentes e gestores devem lembrar-se de que seu papel é o de mediador entre as ideias e as práticas, além de reconstrutor do conhecimento por meio de aprendizagens significativas, relevantes e inovadoras.

\footnotetext{
${ }^{7}$ Lista de Finalistas Etapa Nacional: http://plataforma.gpinovacao.senai.br/plataforma/desafio/34
} 


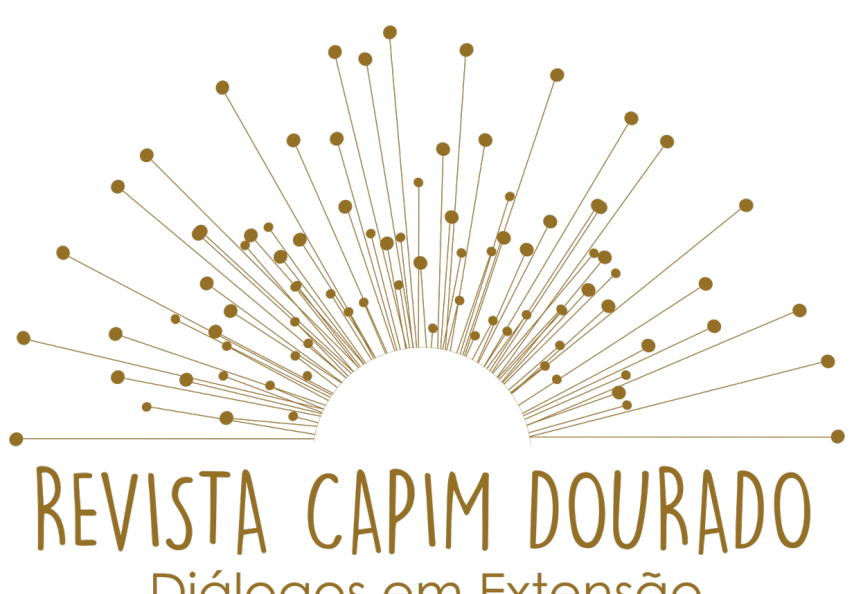

Diálogos em Extensão

ISSN n 2595-7341

Vol. 3, n. 1, Janeiro-Abril, 2020

DOI: http://dx.doi.org/10.20873/uft.2595-7341.2020v3n1p197

\section{REFERÊNCIAS}

ALVES, E. J.; SILVA, B. D. DA. APRENDER "COM" A TECNOLOGIA: O uso do Facebook no processo de aprendizagem e interação de curso online. Revista Observatório, v. 5, n. 4, p. 658-669, 1 jul. 2019.

EVANGELISTA, F.; MARTINS , K. D.; ANGELINI, M. F. C.; ROCHA, M. J. F. Sociedade do conhecimento: $O$ uso das TIC por docentes e as novas articulações de saberes educacionais no sudeste do Pará. Revista Observatório, v. 5, n. 5, p. 188-208, 1 ago. 2019.

FRANCISCATTO, R.; WAGNER, R.; PASSERINO, L. M. Tecnologias e ferramentas para elaboração de conteúdos em um ambiente MOOC: estudo de caso a partir de uma formação em Tecnologias Assistivas. Revista Observatório, v. 4, n. 3, p. 361-398, 29 abr. 2018.

GP INOVAÇÃO. Plataforma SENAI de Gestão e Projetos e Inovação: Desafio Senai de Projetos Integradores. [online] 2017. Disponível em: <http://plataforma.gpinovacao.senai.br/plataforma/desafio/34> Acesso em 07 de out de 2017.

KOTLER, Philip; BES, Fernando Trías De. A BÍBLIA DA INOVAÇÃO: Princípios fundamentais para levar a cultura da inovação contínua às organizações. São Paulo: Editora Leya, 2011.

MASETTO, Marcos. Inovação na Educação Superior. Interface (Botucatu), Botucatu, v. 8, n.14,p.197-202,Feb.2004.acesso em: <http://www.scielo.br/pdf/icse/v8n14/v8n14a17.pdf>. acesso em 06 out. 2017. 


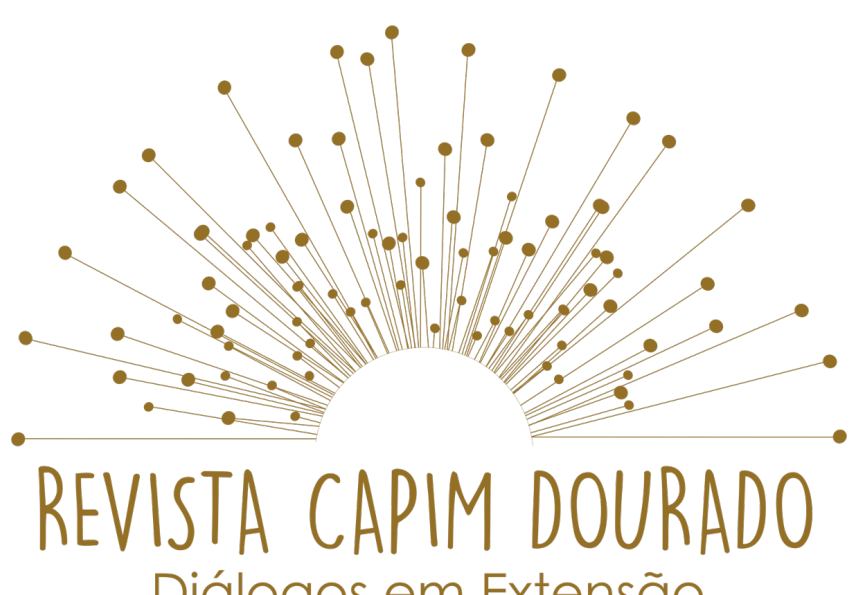

Diálogos em Extensão

ISSN n² 2595-7341

Vol. 3, n. 1, Janeiro-Abril, 2020

DOI: http://dx.doi.org/10.20873/uft.2595-7341.2020v3n1p197

MEGHNAGI, Saul. A competência profissional como tema de pesquisa. Educ. Soc., ampinas, v. 19, n. 64, p. 50-86. 1999. Disponível em: <http://dx.doi.org/10.1590/S0101-73301998000300003 >. Acesso em 07 out. 2017.

OCDE. ORGANIZAÇÃO DE COOPERAÇÃO E DESENVOLVIMENTO ECONÔMICO. Manual de Oslo: Proposta de Diretrizes para Coleta e Interpretação de Dados sobre Inovação. [S. l.]: OCDE; FINEP, 3 Edição, 2005. 184 p.

RODRIGUES, G. F.; SOARES COUTINHO, K. TECNOLOGIA ASSISTIVA PARA INCLUSÃO LABORAL: o que a internet tem a oferecer?. Revista Observatório, v. 4, n. 3, p. 54-84, 29 abr. 2018.

SENAI/TO. Serviço Nacional de Aprendizagem Industrial. Tocantins [online] Disponível em: <http://www.senai-to.com.br/> Acesso em: 06 de out. de 2017. SILVA, F. DOS S.; ALMEIDA, A. C. F. DE; GODOI E SILVA, K. A. O desenvolvimento do pensamento computacional com a integração do software scratch no ensino superior. Revista Observatório, v. 5, n. 1, p. 276-298, 14 jan. 2019.

SILVA, B. D.; SARTORI, A. S.; MARTINI, R. G. As tecnologias de informação e comunicação como agentes de integração do currículo com a glocalidade. Revista Observatório, v. 3, n. 4, p. 387-406, 1 jul. 2017.

SILVA, P. C. Cidade. City. Cité. Smartcity. O espaço contemporâneo do Período Técnico Científico Informacional. Duas experiências globais. Revista Observatório, v. 1, n. 1, p. 233-246, 30 set. 2015.

SOUZA, D. P. DE; BATISTA, C. P.; EVANGELISTA, Y. S. P. ACESSIBILIDADE COMUNICACIONAL NA EDUCAÇÃO: A experiência do Núcleo de Tecnologia 


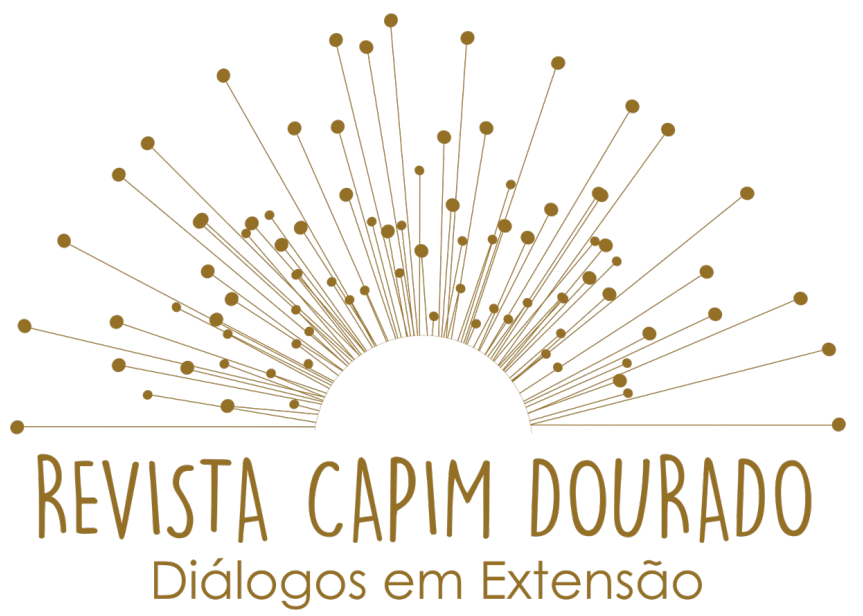

ISSN n² 2595-7341 Vol. 3, n. 1, Janeiro-Abril, 2020

DOI: http://dx.doi.org/10.20873/uft.2595-7341.2020v3n1p197

Assistiva do IFAM na adaptação. Revista Observatório, v. 4, n. 3, p. 85-104, 29 abr. 2018.

SOUZA, M. D. DE; FERREIRA, L. A. A TECNOLOGIA ASSISTIVA CÃES-GUIA NO BRASIL: uma ação do Programa Viver sem Limite. Revista Observatório, v. 4, n. 3, p. 307-336, 29 abr. 2018. 